\title{
Quinto momento de la Quinta República: EI socialismo del siglo XXI
}

\author{
Mujica Chirinos, Norbis* \\ Rincón González, Sorayda**
}

\section{Resumen}

El presente artículo tiene como objetivo precisar qué entiende por socialismo del siglo XXI el actual gobierno venezolano y cuál es modelo de desarrollo que subyace en el mismo. El análisis parte de una caracterización de la Política Social y Económica que los autores del presente trabajo realizaron en 2006 donde determinaron cuatro momentos diferentes por los que ha atravesado el Gobierno actual, planteando que a partir del año 2005 se conforma un quinto momento relacionado con las propuestas alrededor del socialismo del siglo XXI. Posteriormente, se explican las ideas Marxistas acerca del socialismo haciendo énfasis en las áreas económica -propiedad, mercado y producción/productividad-y social-justicia distributiva-; luego trabajan las propuestas de Dieterich y Reyes, autores con posiciones favorables al socialismo, culminando con el examen de dos documentos oficiales: Líneas Generales del Plan de Desarrollo Económico y Social de la Nación 2007-2013y el Plan Nacional Simón Bolívar: Todos los Motores a Máxima Revolución Rumbo al Socialismo, que recogen la visión del Gobierno sobre la materia. La metodología utilizada fue el análisis de contenido y el análisis biblio-hemerográfico. Se concluye que el objetivo del Gobierno es avanzar en dirección a un estadio socialista de transición hacia el comunismo propiamente dicho, con el fortalecimiento de un Estado centralizado, economía mixta con presencia mayor de propiedad Estatal y social que privada y la profundización de la polarización política, que trae como consecuencia nuevas formas de exclusión y el establecimiento de una ciudadanía de tipo selectiva.

Palabras clave: Venezuela, socialismo, marxismo, modelo de desarrollo, política económica, política social.

Recibido: 21-11-07. Aceptado: 21-02-08

* Licenciado en Comunicación Social, mención Periodismo Impreso, de La Universidad del Zulia (LUZ). Especialista en Política Social, Centro de Estudios del Desarrollo (CENDES) de la Universidad Central de Venezuela (UCV). Cursante del Doctorado en Ciencias Sociales. LUZ. Investigador del Centro de Estudios de la Empresa, FCES, LUZ. Acreditado al Programa de Promoción al Investigador (PPI) de la ONCTI. Correo-e: norbism@yahoo.com

** Sociólogo egresada de La Universidad del Zulia (LUZ). Magíster en Planificación y Gerencia de C y T (LUZ). Doctora en Ciencias Gerenciales de la Universidad Rafael Belloso Chacín (URBE). Profesora Titular de la Escuela de Sociología de LUZ. Investigadora del Centro de Estudios de la Empresa, FCES, LUZ. Acreditada al Programa de Promoción del Investigador (PPI) de la ONCTI. Correo-e: sorarincon@hotmail.com 


\title{
Fifth Moment of the Fifth Republic: Socialism of the XXIst Century
}

\begin{abstract}
The objective of this article is to specify what the current Venezuelan government understands by twenty-first century socialism and what development model underlies it. The analysis starts with a characterization of the social and economic policies that this paper's authors made in 2006, when they determined four different phases through which the present Government has passed, and states that, beginning in 2005, a fifth phase began related to proposals about twenty-first century socialism. Marxist ideas about socialism are explained, emphasizing economic areas - property, market and production/productivity- and social areas, such as distributive justice. Next, the proposals of Dieterich and Reyes are studied, authors who hold favorable positions regarding socialism, culminating with the examination of two official documents: General Lines in the Plan for Economic and Social Development of the Nation 2007-2013 and the National Plan Simón Bolívar, all of which are motors for maximum revolution on the road to socialism, and which gather the government's vision on the matter. The methodology used was content and bibliographic-hemerographic analysis. Conclusions are that the government's objective is to advance in the direction of a socialist stage of transition towards communism itself, by fortifying a centralized state, mixed economy with a greater presence of state and social property over private property, and a deepening of political polarization that brings new forms of exclusion and the establishment of a selective type of citizenry.
\end{abstract}

Key words: Venezuela, socialism, Marxism, development model, economic policies, social policies.

\section{Introducción}

La llegada de Hugo Chávez al poder en 1999 marca una ruptura en el estilo y manera de concebir y accionar de la política en el país. Pensamientos y conceptos clave de la anterior democracia representativa son borrados por un estilo particularmente de confrontación que busca eliminar del espectro político el bipartidismo y cualquier otra expresión política característica de la etapa histórica construida luego de la caída de la dictadura en enero de 1958. Así, ideas centrales que caracterizaron esa etapa política, como concertación, consenso, pluralidad, representatividad y amplitud, dan paso a una serie de elementos que giran alrededor de la figura central y emblemática del actual presidente y que van a depender de la coyuntura particular por la cual atraviese el país en un momento determinado.

Tomando en consideración lo anteriormente dicho, se perciben algunos momentos específicos, intimamente relacionados con la concepción y aplicación de la política, que desembocan en lo que actualmente se pretende implementar. Cada uno de estos momentos se construye alrededor de algunas ideas que le dan base a las propuestas de política que lo caracterizan y definen, y que van desde Constituyente, pasando por Desarrollo Endógeno, hasta llegar a lo que hoy se intenta dar contenido: El Socialismo del Siglo XXI. 
Quinto momento de la Quinta República: El socialismo del siglo XXI

Mujica Chirinos, Norbis y Rincón González, Sorayda

En este sentido, el presente esfuerzo trata de dilucidar qué entiende por Socialismo del Siglo XXI el actual gobierno de Venezuela. Para responder a esta interrogante partiremos de los documentos oficiales que recogen las ideas centrales en esta materia y en cuanto a la concepción de las políticas públicas -Plan de Desarrollo Económico y Social de la Nación (PDESN) 2007-2013 (MPD, 2007a) y el Plan Nacional Simón Bolívar (MPD, 2007b)-, particularmente la social y la económica, matizadas con algunos autores que manejan el tema a favor de la idea del socialismo, particularmente la propuesta de Dieterich (2005) y Reyes (2006). Por supuesto, como es lógico, el núcleo central de referencia necesariamente son las ideas que sobre el socialismo están contenidas en la propuesta filosófica Marxista, Así mismo, el análisis se centrará en el modelo de desarrollo que subyace a la propuesta del Socialismo del Siglo XXI, específicamente lo relacionado con la Política Social -particularmente la justicia distributiva- y la Política Económica -lo relacionado con el régimen de propiedad, con la producción/productividad y con el mercado-

\section{Consideraciones previas: algunos momentos del actual gobierno}

En un trabajo anterior (Mujica y Rincón, 2006), se caracterizó la Política Económica y la Política Social del actual gobierno hasta el año 2004, objetivo este que permitió establecer algunos periodos por los cuales, a nuestro modo de ver, ha transitado el mismo a partir del año 1999 y desde donde definimos cuál modelo de desarrollo se intentaba aplicar. Se determinaron cuatro momentos diferentes a partir del análisis de los distintos documentos oficiales en materia económica y social.

El Primer Momento se denomina Del neoliberalismo abierto al ajuste silencioso, y está guiado por dos documentos: la propuesta electoral "Una revolución democrática: La propuesta de Hugo Chávez para transformar Venezuela" (MVR, 1998) y en segundo término por el "Programa económico de transición 1999-2000" (Coordiplan, 1999a) que abarcan fundamentalmente el primer año de gobierno, de febrero a diciembre de 1999. Básicamente se consideró que era un momento en el que se debió pasar del neoliberalismo característico del gobierno anterior a otra propuesta distinta en términos de política económica y social; sin embargo, se percibe que el paso fue hacia un ajuste silencioso de características similares a los intentados en los años 1989 y 1996.

La contradicción fundamental se aprecia desde el punto de vista de la concepción general del modelo de desarrollo propuesto, opción tercerista con participación económica activa del Estado democratizando el capital y el mercado, y las políticas aplicadas, típicamente de ajuste estructural en cuanto a la concepción de la política macroeconómica -control inflacionario- y su relación con la política social -compensatoria y focalizada-, aun y cuando se asume que la misma tendrá un carácter integral y universal (Cf: MVR, 1998; Cordiplan, 1999a; MPD, 2000a).

Es decir, la base normativa de lo que al inicio de la actual gestión se llamó "Quinta República" se alejan y separan 
de los principios liberales y neoliberales; sin embargo, a pesar de presentar avances desde el punto de vista del pensamiento que guía la política, se trazaron también propuestas de ajuste macroeconómico y política social compensatoria, centralizada y coordinada desde el Plan Bolívar 2000 (PB-2000) y el Fondo Único Social (FUS), típicas de las políticas que caracterizaron el ajuste estructural aplicadas por los gobiernos de Carlos Andrés Pérez (CAP) y Rafael Caldera (RC) y promovidos por el Banco Mundial (BM) y el Fondo Monetario Internacional (FMI), lo que evidencia contradicciones en la concepción general de la política a aplicar.

De manera tal que para este primer momento la acción gubernamental giró alrededor de una política centralizada en estructuras, en recursos y expansiva en gasto, lo que demuestra contradicciones en cuanto a la formación y formulación de la política; es decir, las políticas de ajuste propuestas chocan con los principios del modelo propuesto; incluso hay autores (Machado, 2000; Castellano, 2003; Gómez, 2003) que afirman que el ajuste de 1999 fue más severo que el de 1989.

El Segundo Momento, titulado De Principios y Contradicciones y abarca el periodo de enero de 2000 a diciembre de 2001. Es un momento de definiciones filosóficas y normativo-programáticas que busca delimitar teórica y estratégicamente los principios que regirán la acción económico-social gubernamental. Varios documentos oficiales guían este período: en primera instancia tendríamos el Programa de Gobierno: La Propuesta de Hugo Chávez para Continuar la Revolución (MPD, 2000a), el Programa Económico Año 2000 (MPD, 2000b), el Programa
Económico 2001 (MPD, 2001a) y las Líneas Generales del Plan de Desarrollo Económico y Social de la Nación 20012007 (PDESN, 2001-2007) (MPD, $2001 \mathrm{~b}$ ); este grupo se complementan con el documento La Revolución Social de la $\checkmark$ República: La Política Social de Venezuela (MSDS, 2000), presentado por el Ministerio de Salud y Desarrollo Social (MSDS) como la política social de Venezuela ante la Cumbre Mundial de Desarrollo Social celebrada en Ginebra, Suiza, en Junio de 2000, redactado en base a los derechos sociales contenidos en la nueva constitución.

En este período los objetivos de los programas económicos 2000 y 2001 gobierno coinciden con los planteamientos de los planes del período anterior, relacionado con el fin último de control inflacionario de la política macroeconómica. Todos ellos consiguen concreción definitiva en las Líneas Generales del Plan de Desarrollo Económico y Social de la Nación 2001-2007 (MPD, 2001b); es decir, se mantiene los mismos principios tanto de la política económica y la política social, con algunos matices en esta última en cuanto a su concepción teórica-filosófica, pues recoge ideas de avanzada relacionadas con el disfrute de los derechos sociales constitucionales (Cf: Mujica y Alvarado, 2004). Sin embargo, la estrategia continuó centrada en el FUS y el PB2000. En este sentido, se mantienen las contradicciones en cuanto a la fundamentación y ejecución de la política que el periodo anterior.

De esta forma, en cuanto a la concepción de la política macroeconómica y la política social, podemos caracterizar la gestión gubernamental y su concepción 
Quinto momento de la Quinta República: El socialismo del siglo XXI

Mujica Chirinos, Norbis y Rincón González, Sorayda

de Estado, para los primeros dos períodos, como de neoliberal moderado, con matices neoestructurales e inclinaciones nacionalistas (Mujica, 2002).

El Tercer Momento se define de Rupturas y Conspiraciones, decisivo para la continuidad de la Quinta República, pues, producto de comportamientos económicos que se arrastraban desde finales de 2001, se producen quiebres importantes en las concepciones de políticas, reflejados en cambios de gabinetes y conspiraciones contra el gobierno y abarca el año 2002.

Los documentos que guían este periodo son cuatro, a saber, Medidas en Materia Fiscal, Cambiaria y Productiva (MPD; 2002a), Se Garantiza la Inversión Social y se Incentiva la Producción (MPD, 2002b), Propuesta para el Consenso (MPD, 2002c) y el Plan Estratégico Social 2001-2007 (MSDS, 2002).

Es importante resaltar que las medidas contenidas en estos documentos, particularmente el primero y el segundo, inclinadas hacia las ideas liberales y neoliberales, se producen por la importante fuga de divisas producida a finales de 2001 y los recortes de la producción acordados por la Organización de Países Exportadores de Petróleo (OPEP) para tratar de mantener el precio ${ }^{1}$. A comienzos de 2002 se hizo evidente un déficit fiscal, lo que obligó al gobierno a replantear la política macroeconómica.

Fundamentalmente, las medidas más importantes se toman en materia fiscal y cambiaria, particularmente esta última, pues se asume el sistema de libre flotación o flotación limpia, con lo que el precio de la divisa lo determinaría el libre juego de la oferta y la demanda. Este esquema se articularía con una política fiscal restrictiva, dirigida a conferirle viabilidad a la gestión financiera del Estado; es decir, se impone la disciplina fiscal ${ }^{2}$, con lo que el ancla nominal de precios deja de ser el tipo de cambio para centrarse en esta última, configurada como el elemento central de la estabilidad macroeconómica.

Como complemento se toman un conjunto de medidas en materia social que prioriza ciertos sectores -Seguridad Alimentaria, Atención Integral, Infraestructura Social y Plan Bolívar 2002- para garantizar un mínimo de inversión, con lo que se restringe aun más recursos y poblaciones objetivos de la política social. Como se aprecia, se sigue con la misma orientación cortoplacista y compensatoria de la política social, aun y cuando existe un programa nacional de desarrollo a mediano plazo.

1 La estimación del precio del barril de petróleo para el presupuesto de 2002 tuvo que ser ajustado de $\$ 18,5$ a $\$ 16$. Así mismo, las reservas brutas (incluyendo el FIEM) entre diciembre de 2001 y la primera semana de febrero de 2002 , cayeron en $\$ 2.950$ millones, lo que las ubicó en \$16.633 (Cabezas, 2002; Chávez, 2002).

2 Muchos expertos dudaron, con mucha razón, de los resultados de la aplicación de esta política, pues la experiencia del país nos dice que somos indisciplinados fiscalmente hablando; es decir, cuando hay recursos se expande el gasto sin ningún tipio de pensamiento estratégico que oriente la sostenibilidad del mismo, y en momentos de crisis se contrae. 
La presión sobre el índice de precios al consumidor que generaron estas medidas -que obligó al gobierno a revisar su meta inflacionaria-, aunado al ambiente político provocado por el paro nacional de diciembre de 2001 convocado por la Confederación de Trabajadores de Venezuela (CTV) y la Federación de Cámaras de Comercio y Producción (Fedecámaras), hizo crisis el 11 de abril de 2002, provocando la salida por 48 horas del presidente Hugo Chávez. Las consecuencias más importantes, desde el punto de vista del enfoque del presente trabajo, fueron, en primer lugar, que genera cambios en el Gabinete, particularmente en el Ministerio de Planificación y Desarrollo (MPD) -sale Jorge Giordani y asume Felipe Pérez- y en el Ministerio de Finanzas -sale Héctor Merentes e ingresa Tobías Nóbrega-, y, en segundo lugar, genera otro programa de corto plazo, Propuesta para el Consenso (MPD, 2002c).

A partir de la aparición de este documento, se asume, en términos teóricos-filosóficos, otro enfoque que el jefe del equipo económico denomina cuarta vía y que en lo económico combina los dos mecanismos tradicionales de asignación de recursos -Estado y Mercado- y agrega la solidaridad como tercer elemento (Pérez y Rodríguez, 2000; Pérez, 2001; 2002). Sin embargo en la práctica se continúa casi con la misma orientación de los planes anteriores: énfasis en la política fiscal como fundamento de la estabilidad de precios y palanca de la estabilidad macroeconómica y se priorizan aun más los sectores de actuación de la política social, a saber: Atención a la Infancia, Alimentación y Nutrición, Protección Social de Adultos Mayores e Infraestructura Social Básica.
El avance, desde el punto de vista meramente declarativo, se expresa en los principios -el crecimiento está reñido con la desigualdad, crecimiento desde abajo, participación abierta a todos los sectores del país, reconocimiento del papel de los empresarios y clase media- y las áreas propuestas para el consenso -sector académico y Gobierno; sector privado, trabajadores y comunidades de Base; medios de comunicación; y centros académicos y financieros internacionales (BM, FMI, Banco Interamericano de Desarrollo (BID), Corporación Andina de Fomento (CAF), Sistema Económico Latinoamericano (SELA)- como camino para la creación de expectativas favorables que permitieran recuperar la senda del crecimiento, separando la economía del disenso político (MPD, 2002c).

Coincidencialmente, igual que en el segundo momento, el MSDS publica un documento de orientación y planificación de políticas sociales que se separa de las líneas que presentan los planes anteriormente discutidos. En efecto, el Plan Estratégico Social 2001-2007 (MSDS, 2002), recoge las guías estratégicas para transformar las condiciones de vida de la población en base a los derechos sociales, valores y principios consagrados en la constitución y en el PDESN 2001-2007.

Articulado en torno a tres ejes conceptuales -universalidad con equidad vs. Focalizaciyn y pobreza; brechas por inequidad vs. Dйficit de atenciyn; transectoralidad vs. sectorializaciyn- propone cuatro directrices estratŭgicas: 1 . Orientar las poluticas pъblicas para responder a las necesidades sociales de calidad de vida y salud con equidad y universalidad; 2 . Asumir la esta estrategia mediante la transec- 
Quinto momento de la Quinta República: El socialismo del siglo XXI

Mujica Chirinos, Norbis y Rincón González, Sorayda

torialidad en funciyn de territorios sociales, buscando la autonomra individual y colectiva y dejando saldos organizativos; 3. Desarrollar nuevos modelos de atenciyn que reordenen recursos, capacidades nacionales-regionales-locales y formen redes sociales; 4 . Construir una nueva institucionalidad pъblica de lo social.

Como se evidencia, el documento representa un avance importante en la concepción de la política social, pues pone en el centro del debate el problema de la equidad y universalidad en el marco de los derechos constitucionales, más sin embargo, se continúa centrando las acciones en planes cortoplacistas.

El Cuarto Momento se denomina Salto Atrás, pues producto de los acontecimientos políticos -paro cívico indefinido que comienza en diciembre de 2002 y se extiende hasta el primer trimestre de 2003- y sus consecuencias desastrosas, se asumen estrategias de políticas que caracterizaron gobiernos anteriores de la democracia representativa, despectivamente llamados de la cuarta república, además de significar un cambio en la aplicación de la política social.

En términos de política económica, se establece un control de cambio y de precios a productos de consumo masivo y de servicios, con lo que nace la Comisión de Administración de Divisas (CADIVI) como organismo encargado de ejecutar la que seria en adelante la política cambiaria del Gobierno. Así, el ancla nominal de precios vuelve a ser la política cambiaria.
También se producen cambios en el gabinete económico que marcan el retorno de Jorge Giordani, antiguo titular del Ministerio de Planificación y Desarrollo y del equipo económico, que converge con el nacimiento de un nuevo discurso gubernamental alrededor del Desarrollo Endógeno como estrategia de crecimiento.

Con el regreso del ministro, se retoma la idea de transitoriedad o transición como fase previa a otra etapa de sostenibilidad del crecimiento basado en tres impulsores que buscan contrarrestar las consecuencias del paro: la inversión pública -política fiscal expansiva-, la inversión privada y las misiones sociales como expresión de una política social más estructural e inclusiva.

En cuanto a la naturaleza de las Misiones Sociales, no existe consenso entre los autores; unos las consideran estratégicamente más inclusivas, mientras que otros las consideran focalizadas y compensatorias (Alvarado, 2004; Maingón, 2006). Aun cuando conservan rasgos de una y de otra posición, lo que dificulta su ubicación en alguna tendencia teórica, en términos generales se puede afirmar que así como intentan resolver el problema de la inclusión y equidad, caen en las mismas, al no reconocer como poblaciones objetivos a sectores importantes de la población, como la clase media y profesional, que quedan fuera de su foco de atención trayendo como consecuencia nuevas formas de exclusión ${ }^{3}$, exclu-

3 La expresión más conocida en el país de estas nuevas formas de exclusión fue la denominada Lista Tascón, suerte de lista negra construida por el Diputado Oficialista Luis Tascón y puesta a 
sión selectiva y autoexclusión; la primera, definida por el no acceso a servicios fundamentales del Gobierno de aquellas personas que lo adversan -no pueden contratar con el Estado, no pueden conseguir empleo en cargos públicos, se le dificultan procesos como la cedulación y pasaporte, no pueden acceder a los programas sociales, etc.-; y la segunda, consecuencia de la primera, la decisión de las personas a ni siquiera intentar acceder a los servicios sociales dada la actitud del gobierno ante sus adversarios.

Esta manera de concebir la convivencia democrática conforma una ciudadanía selectiva o ciudadanía dividida como expresión de la polarización política, según la cual sólo son ciudadanos con derechos los que apoyan al Gobierno, mientras los otros son pseudos ciudadanos, únicamente con deberes -respeto a las leyes y pagadores de impuestos y tarifas públicas diferenciales-.

Así mismo, la aparición de estos nuevos fenómenos sociales, pone de manifiesto el uso de las Misiones como ins- trumento de populismo electoral, proselitismo ideológico y control político. Hay que recordar que las mismas nacen luego del paro petrolero y previo al referendo revocatorio de 2003.

\section{Quinto Momento: El socialismo del siglo XXI: Nuevo discurso desde el poder}

Del análisis hecho hasta el momento, se desprende que ha existido una contradicción entre los planteamientos recogidos por los documentos oficiales y sus ejecutorias de políticas que se expresan en acercamientos y alejamientos de la concepción neoliberal. Por ejemplo, la concepción de Estado como opción tercerista u opción cuarta vía no encaja en visión la neoliberal, pero se aplican políticas dentro del marco del mismo, como la fusión y reducción de ministerios ${ }^{4}$, aunque en el último momento estudiado se crearon un número significativo de estos -Ministerio de la Vivienda y Hábitat, Minis-

navegar en la Red a través de su página web www.luistascon.com, con información confidencial del Consejo Nacional Electoral referida a los firmantes de la solicitud del Referendo Revocatorio Presidencial en el año 2003. Esta lista, según la opinión de especialistas y de la misma Corte Interamericana de Derechos Humanos, es una clara manifestación de la discriminación y segregación ideológica como política de Estado, mecanismo perverso que permitió depurar las dependencias públicas y empresas del Estado de los ciudadanos que no comulgaban con sus políticas y propuestas. Otro ejemplo lo constituye el video divulgado en noviembre de 2006, previo a las elecciones presidenciales de diciembre, donde el Ministro de Energía y Petróleo y Presidente de PDVSA, Rafael Ramírez, increpa a los trabajadores de la estatal petrolera a votar por el Presidente Chávez, además de afirmar que la empresa era "roja, rojita". Otro ejemplo reciente es el de la Empresa Sincrudos de Oriente (Sincor), donde los trabajadores son clasificados como Aptos y No Aptos según su inclinación política; además, para poder trabajar en la misma se debe pertenecer a alguna de las Misiones y los días viernes usar una franela roja. Ver: Clarembaux (2007); Azocar (2007); Soto (2006); Jatar (2006)

4 Hoy son llamados Ministerios del Poder Popular. 
Quinto momento de la Quinta República: El socialismo del siglo XXI

Mujica Chirinos, Norbis y Rincón González, Sorayda

terio de la Economía Social, Ministerio de Educación Superior, Ministerio de Energía y Petróleo, Ministerio de Minas e Industrias Básicas, Ministerio para la Participación y el Desarrollo Social, entre otros-.

Por otra parte, la política petrolera es contraria a las tendencias neoliberales, así como el control sobre el tipo de cambio y la política fiscal expansiva, la política de estatización de empresas estratégicas -Compañía Anónima Nacional Teléfonos de Venezuela (CANTV), Electricidad de Caracas y más recientemente la Siderúrgica del Orinoco (SIDOR)-, la expropiación de fincas, la tendencia hacia la centralización de las decisiones del Estado, entre otras, en el último momento estudiado.

De esta manera se podría afirmar que lo que se persigue, hasta lo aquí analizado, es el establecimiento de un modelo de desarrollo que armonice acumulación y distribución con participación activa Estatal, configurando una sociedad de economía mixta con un Estado activo y fuertemente centralizado, desde el punto de vista económico, como empresario y promotor de inversiones. Es desde este planteamiento donde se armó el discurso del Desarrollo Endógeno, que copo el escena gubernamental a partir del 2003, posterior al paro nacional y previo al referéndum revocatorio.
Luego del triunfo en el revocatorio, el Gobierno comienza a replantear sus propuestas alrededor de una nueva idea, ratificado por el propio Chávez en el Foro Social Mundial de enero de 2005: el Socialismo del Siglo XXI, tendencia que es corroborada y profundizada luego de la victoria electoral de diciembre de 2006.

En este sentido, se considera que a partir de 2005 se conforma un nuevo momento dentro de la caracterización de la gestión gubernamental, Quinto momento que titulamos El Socialismo del Siglo XXI, cuya configuración es preparada por las decisiones políticas aplicadas en el momento anterior relacionadas con el control de cambios y de precios, la centralización política y el fortalecimiento del Estado central, la re-estatización de empresas estratégicas, las expropiaciones de fincas, las amenazas de estatizar el sistema bancario -entre otras-, así como también el diseño y ejecución de las Misiones Sociales como expresión de populismo político, control social y exclusión selectiva (que lo acerca mucho a la experiencia del socialismo real del pasado siglo $X X)^{5}$.

Para intentar bosquejar este quinto momento, partiremos de las ideas que sobre el socialismo plantea la filosofía Marxista como base fundamental de discusión; posteriormente, se pondrá sobre el tapete los planteamientos que sobre el Socialismo del Siglo XXI plantea Heinz

5 Aun y cuando en el Referendo de Diciembre de 2007 la mayoría de los ciudadanos votó contra la reforma constitucional, propuesta por el Ejecutivo y avalada y ampliada por la Asamblea Nacional, que pretendía dar rango constitucional a las ideas socialistas, las actuaciones y el discurso desde el Gobierno luego de los comicios nos permiten afirmar que no existe voluntad para cambiar el rumbo político y se sigue actuando alrededor de las ideas socialistas sin respetarse los resultados electorales. 
Dieterich Steffan (2005), como ideólogo y asesor de la Presidencia de la República, para luego trabajar los planteamientos del Prof. Oscar Reyes (2006), investigador-docente de la Universidad Católica Andrés Bello, quien, por petición del Viceministro de Comunicaciones William Castillo, elaboró un artículo que intenta bosquejar algunas instituciones de transición hacia un nuevo modelo societal que llama socialismo del siglo XXI. Se concluirá con la propuesta gubernamental contenida en dos documentos básicos: Líneas Generales del Plan de Desarrollo Económico y Social de la Nación 20072013 (MPD, 2007a) y el Proyecto Nacional Simón Bolívar: Todos los Motores a Máxima Revolución Rumbo al Socialismo (MPD, 2007b).

Así mismo, el núcleo central del análisis girará en torno al planteamiento de las políticas públicas referidas a lo económico -problema de la propiedad, el mercado y la producción/productividad- y lo social -justicia distributiva- para a partir de allí intentar definir el modelo de desarrollo en la propuesta del Socialismo del Siglo XXI.

\subsection{Marx y el Socialismo}

La filosofía Marxista surgió a mediados del siglo XIX como una crítica teórica al sistema de producción capitalista y como propuesta de emancipación de la clase obrera, específicamente en Europa Occidental. Las investigaciones y estudios de Marx sobre la economía capitalista europea señalan que el modo de producción capitalista, basado en la explotación y apropiación del trabajo asalariado por el capital, llevaba en sí misma la con- tradicción fundamental entre el carácter social de la producción y el carácter de la apropiación de la riqueza generada. La apropiación del trabajo por el capital -la ganancia- Marx la llamó Plusvalía - trabajo no remunerado-, considerada por él como única fuente de riqueza (Marx, 1972, 1976, 1977).

Siendo los capitalistas dueños del capital, producto de la apropiación del plustrabajo, y siendo los trabajadores dueños sólo de su fuerza de trabajo, la abolición de la propiedad privada era el camino para superar la contradicción y democratizar la actividad productiva.

"La propiedad privada nos ha hecho tan estúpidos y unilaterales que un objeto sólo es nuestro cuando lo tenemos, cuando existe para nosotros como capital o cuando es inmediatamente poseído, comido, bebido, vestido, habitado, en resumen, utilizado por nosotros. Aunque la propiedad privada concibe, a su vez, todas estas realizaciones inmediatas de la posesión sólo como medios de vida y la vida a la que sirven como medios es la vida de la propiedad, el trabajo y la capitalización (...) La superación de la propiedad privada es por ello la emancipación plena de todos los sentidos y cualidades humanos; pero es esta emancipación precisamente porque todos estos sentidos y cualidades se han hecho humanos, tanto en sentido objetivo como subjetivo" (Marx, 1972: 148).

La única vía por la cual la clase obrera podría conseguir la supresión de la propiedad privada era a través de la lucha política por el poder a través de una revolución social y la instauración de lo que Marx Ilamó la Dictadura del Proleta- 
Quinto momento de la Quinta República: El socialismo del siglo XXI

Mujica Chirinos, Norbis y Rincón González, Sorayda

riado ${ }^{6}$ como garantía de avance hacia un sistema social perfecto y distinto del capitalista, que llamó Comunismo.

"El objetivo inmediato de los comunistas es idéntico al que persiguen los demás partidos proletarios en general: formar la conciencia de clase del proletariado, derrocar el régimen de la burguesía, llevar al proletariado a la conquista del Poder" (Marx y Engels, 2005:34). "Para nosotros, el comunismo no es un estado que debe implantarse, un ideal al que haya que sujetarse la realidad. Nosotros llamamos comunismo al movimiento real que anula y supera el estado de cosas actual (...) Su acción sólo puede llegar a cobrar realidad como existencia histórica universal de los individuos, es decir, existencia de los individuos directamente vinculada a la historia universal (Marx y Engels, 1982:36).

Marx concibió la idea del Socialismo como una etapa previa al establecimiento del Comunismo. Esta etapa previa estaría basada en la Dictadura del Proletariado, conformada por los obreros en el poder. Consideraba que el proletariado era la única clase social realmente revolucionaria, puesto que eran los que sufrían en carne propia la explotación capitalista. Esta fase de la dictadura del proletariado era un tránsito a la abolición de todas las clases y hacia una sociedad $\sin$ clases; en ella los obreros en el poder su- plantarían al Estado burgués -no hay que olvidar que para Marx, el Estado formaba parte de las instituciones burguesas que perpetuaban la explotación y sometimiento obrero-.

"Ya dejamos dicho que el primer paso de la revolución obrera será la exaltación del proletariado al Poder, la conquista de la democracia. El proletariado se valdrá del Poder para ir despojando paulatinamente a la burguesía de todo el capital, de todos los instrumentos de la producción, centralizándolos en manos del Estado, es decir, del proletariado organizado como clase gobernante, y procurando fomentar por todos los medios y con la mayor rapidez posible las energías productivas. Claro está que, al principio, esto sólo podrá llevarse a cabo mediante una acción despótica sobre la propiedad y el régimen burgués de producción" (Marx y Engels, 2005:49). El comunismo, como superación positiva de la propiedad privada en cuanto autoextrañamiento del hombre, y por ello como apropiación real de la esencia humana por y para el hombre; por ello como retorno del hombre para sí en cuanto hombre social, es decir, humano (...) es la verdadera solución del conflicto entre el hombre y la naturaleza, entre el hombre y el hombre, la solución definitiva del litigio entre existencia y esencia, entre objetivación y autoafirmación, entre libertad y necesidad, en-

6 Frederich Engels, en la Introducción a la Tercera Edición de La Guerra Civil en Francia, en 1891, escribió "Últimamente, las palabras "dictadura del proletariado" han vuelto a sumir en santo horror al filisteo socialdemócrata. Pues bien, caballeros, ¿queréis saber qué faz presenta esta dictadura? Mirad a la Comuna de París: ¡he ahí la dictadura del proletariado! 
tre individuo y género. Es el enigma resuelto de la historia y sabe que es la solución" (Marx, 1972:143).

Para Marx, la importancia del sistema político-democrático radicaba en la distribución de la riqueza y la abolición de la propiedad privada, aun cuando no le dio tanta importancia como al análisis económico.

"(...) Es equivocado, en general, tomar como esencial la llamada distribución y hacer hincapié en ella, como si fuera lo más importante. La distribución de los medios de consumo es (...) un corolario de la distribución de las propias condiciones de producción. Y esta distribución es una característica del modo mismo de producción (...) Si las condiciones materiales de producción fuesen propiedad colectiva de los propios obreros, esto determinaría, por sí solo, una distribución de los medios de consumo distinta de la actual (Marx, 1974a:16).

Marx dibujó el estadio de dictadura del proletariado en su análisis de la Comuna de París, trazándolo como un régimen basado en un nuevo Estado o negación del Estado burgués centralizado ${ }^{7}$ -que llamó comuna-, de carácter federal, basado en la autonomía local y regional -descentralizado-, conformado por dele- gados electos por sufragio universal y revocables en todo momento -estos delegados recibirían salarios iguales a los de los obreros-. La misma no era un organismo parlamentario, sino un espacio de trabajo ejecutivo y legislativo al mismo tiempo (Marx, 2003).

En esta fase, los cuerpos armados -ejército y policía- desaparecerían para dar paso a las milicias organizadas en cada localidad; así mismo, establece la separación entre Estado e Iglesia y la expropiación de estas últimas como corporaciones poseedoras. Los magistrados y jueces igualmente serían electos y revocables en todo momento, y las organizaciones educativas fueron abiertas a todo el pueblo y despojadas de toda influencia tanto del Estado como de la Iglesia.

Si bien desaparecería el Estado, no así la unidad de la nación organizada ahora en base a las autonomías locales mediante un régimen comunal. Esta sería la única forma de garantizar una transición hacia el comunismo, donde Estado e instituciones desaparecerían para dar paso a una sociedad verdaderamente humana. Es importante destacar que la producción en las fábricas se organizaría cooperativamente por los obreros y regularían la producción nacional, evitando la

7 La Guerra Civil en Francia es una de las más importantes obras del marxismo, en la que, sobre la base de la experiencia de la Comuna de París, se desarrollan las principales tesis de la doctrina marxista sobre el Estado y la revolución. En este trabajo se confirma y se desarrolla la tesis expuesta por Marx en El 18 Brumario de Luis Bonaparte acerca de la necesidad de que el proletariado destruya la máquina estatal burguesa. Marx saca la conclusión de que la clase obrera no puede limitarse simplemente a tomar posesión de la máquina del Estado tal y como está y servirse de ella para sus propios fines. El proletariado debe destruirla y sustituirla con un Estado del tipo de la Comuna de París. 
Quinto momento de la Quinta República: El socialismo del siglo XXI

Mujica Chirinos, Norbis y Rincón González, Sorayda

anarquía productiva; es decir, la decisión de qué, cómo y cuánto producir (Marx, 2003).

Esta aseveración es importante, pues aun cuando Marx no elaboró una teoría acabada acerca del mercado como tal, o qué institución de la fase socialista sustituiría al mismo, sí elaboró una teoría del valor -donde se fundamenta las propuestas del socialismo del siglo XXI-; como se apuntó anteriormente, Marx consideraba que el trabajo era la única fuente de riqueza, específicamente, la apropiación de la plusvalía por parte del capital. Así, lo que determina el valor de una mercancía es la cantidad de sustancia creadora de valor, es decir, el trabajo que encierra; éste se mide por el tiempo de su duración y el tiempo de trabajo tiene su medida en las distintas facciones de tiempo. Así, lo que determina la magnitud de valor de un objeto no es más que la cantidad de trabajo socialmente necesario para su producción (Marx, 1972; 1974b; 1976; 1977).

En este sentido, más allá de satisfacer necesidades humanas -que le confiere el carácter de valor de uso-, en la mercancía se encierra el trabajo humano, cualidad que permite su intercambio con otras mercancías, generalizando de esta manera la categoría valor como elemento común del intercambio. Esta es la base de la tesis Marxista de la explotación: el trabajador vende su fuerza de trabajo para producir valores de cambio que contienen un plusvalor respecto del salario devengado, que es apropiado por el capitalista y que representa la ganancia; así, el trabajador siempre se reproducirá como tal vendiendo su fuerza de trabajo De allí también se desprende lo que Marx llama el fetichismo de la mercancía, que esconde en una simple relación entre objetos una relación social mediada por el aporte del trabajo a su creación, lo que define en sí lo que es el trabajo alienado (Marx, 1972; 1974b; 1976; 1977).

El sueño dorado de Marx era cómo devolver a los obreros la plusvalía, que les pertenecía en justicia, pues en vez de realizarse en la actividad humana -el trabajo- eran extraños a lo que producian, realizándose en actividades más biológicas y simples (Cf: Reyes, 2006). Es decir, su preocupación central estaba en cómo distribuir con justicia la riqueza que era arrebatada al obrero. En este sentido, la frase que mejor recoge la idea de cómo distribuir la riqueza la expresa Marx en la Crítica del Programa de Gotha.

"En la fase superior de la sociedad comunista, cuando haya desaparecido la subordinación esclavizadora de los individuos a la división del trabajo, y con ella, la oposición entre el trabajo intelectual y el trabajo manual; cuando el trabajo no sea solamente un medio de vida, sino la primera necesidad vital; cuando, con el desarrollo de los individuos en todos sus aspectos, crezcan también las fuerzas productivas y corran a chorro lleno los manantiales de la riqueza colectiva, sólo entonces podrá rebasarse totalmente el estrecho horizonte del derecho burgués, y la sociedad podrá escribir en su bandera: ¡De cada cual, según su capacidad; a cada cual, según sus necesidades! (Resaltado nuestro)" (Marx, 1974a:15).

Este principio sería sólo posible en la fase superior de la sociedad comunista, con la desaparición del trabajo alienado y, con ella, la división manual e intelectual del trabajo. 
Marx consideraba que en la fase inferior -socialista- necesariamente se aceptarían los defectos heredados de la sociedad capitalista en cuanto al Derecho Igual burgués, en el sentido que el derecho de los productores es proporcional al trabajo que han rendido, pues reina el mismo principio que regula el intercambio de mercancías, por cuanto éste es intercambio de equivalentes. Así, en lo que se refiere a la distribución de los medios de consumo entre productores rige el mismo principio que en el intercambio de mercancías equivalentes: se cambia una cantidad de trabajo, bajo una forma, por otra cantidad igual de trabajo, bajo otra forma distinta (Marx, 1974a).

Para Marx, el derecho igual burgués era un derecho desigual para trabajo desigual, pues no reconocía distinción de clase e ignoraba características propias de los individuos, y aunque lo aceptaba en una primera fase preparatoria al comunismo, lo consideraba, como todo derecho, derecho de la desigualdad.
Pensaba que el derecho sólo podía ser, por naturaleza, la aplicación de una medida igual a individuos desiguales; es decir, no tendría que ser igual, sino desigual (Marx, 1974a).

\subsection{El Socialismo del Siglo XXI: La Propuesta de Dieterich}

En este aparte se analizarán básicamente con los aportes de Heinz Dieterich Steffan (2005), ideólogo y asesor de la Presidencia de la República, La propuesta de Dieterich -El Nuevo Proyecto Histórico: Democracia Participativa-Socialismo del Siglo XXI- gira alrededor de dos ejes fundamentales: primero, la Economía de las Equivalencias, y segundo la Democracia Directa.

Con respecto al Primer Eje, la Economía Planificada de Equivalencias, tomada por Dieterich del economista alemán Arno Peters ${ }^{8}$, se basa en la teoría Marxista del valor trabajo y el intercambio de equivalentes, a partir de la cual se

8 Según Peters, la actual economía de mercado es producto de la evolución histórica de la ciencia económica que, en sus orígenes, era de naturaleza equivalente; es decir, en los orígenes mismos del hombre, éste utilizaba los productos elaborados como medios de intercambio de otros productos cuyo valor era equivalente en trabajo al intercambiado. Con el avance de la ciencia, la técnica y las relaciones sociales, surgieron intereses y valores que llevaron al establecimiento de una economía que, más que satisfacer las necesidades propias del hombre, buscaba la acumulación de riqueza, lo que marca el nacimiento de la propiedad. En el análisis de los inicios de la teoría económica, Peters retoma a Aristóteles, quien consideraba a la economía no como ciencia autónoma, sino como dependiente de la Política y la Ética, por lo que sus ideas sobre la economía no dejan de ser una teoría del Estado. Lo importante del pensamiento aristotélico es la distinción que hace entre economía- arte de la adquisición cuya sustancia es la creación de los medios que son necesarios para el sustento de la familia y el Estado; es decir, el cubrimiento de las necesidades-y la crematística (enriquecimiento)-un segundo tipo de arte de la adquisición que, al contrario del primero, no es una pretensión de la naturaleza, sino que fue añadido artificialmente a ella-. Con la aparición del dinero, se inició el segundo tipo de arte de la adquisición, el comercio, el cual ya no está destinado a la satisfacción de las necesidades, sino sólo a obtener la mayor ganancia posible. 
Quinto momento de la Quinta República: El socialismo del siglo XXI

Mujica Chirinos, Norbis y Rincón González, Sorayda

construyen nuevas relaciones de producción y de propiedad con los medios de producción. De lo que se trata es de reemplazar, gradualmente, el principio regulador de la economía de mercado -el precio-, por el principio regulador de la economía socialista -el valor-, entendido como los insumos de tiempo necesarios para la generación de un producto (Dieterich, 2005; Guerra, 2006).

"Si analizamos la economía y su historia con respecto a la totalidad de los principios que crearon su base, encontramos sólo dos arquetipos: la economía equivalente, bajo cuyo régimen la humanidad ha vivido durante casi 800 mil años desde el inicio de su historia económica, y la economía no-equivalente, la cual hace aproximadamente 6 mil años empezó a poner la economía sobre una nueva base, y que sometió a todo el mundo a su sistema (...) Este tipo de economía, coordinada de manera inestable, antidemocrática y depredadora por el mercado, será sustituida por la economía democráticamente planificada. Que la nueva economía de equivalencias sea planificada, no debe asustar a nadie. No ha habido en la historia una economía no-planificada. El hombre no tiene la opción entre planificación o noplanificación de su sistema material de reproducción, sino solamente entre diferentes tipos y colectivos humanos de planificación" (Dieterich, 2005: 20 y 40).

La palabra equivalente, en este sentido, es clave; viene de valor, que se entiende por cantidad de tiempo. Lo importante, entonces, es la cantidad de tiempo y no el trabajo concreto; es decir, el tiempo de trabajo necesario para producir esos valores. Es importante tam- bién la igualdad de los valores; en una economía de equivalencias los intercambios y gratificaciones de los sujetos económicos se realizarían sobre valores iguales, o sea, sobre esfuerzos laborales y cantidad de trabajo aportado a la generación de riqueza social. En este elemento radicaría la justicia.

"Los países comunistas, igual que los países capitalistas (...) sólo pueden realizar históricamente el regreso a la economía equivalente a un nivel superior, si combinan la teoría sobre el valor del trabajo con el principio de la equivalencia (sic). Entonces el salario equivaldrá al tiempo de trabajo invertido, independientemente de la edad, del sexo, del estado civil, del color de la piel, de la nacionalidad (etc.) (...) En pocas palabras, el salario equivale directa y absolutamente (sic) al tiempo laborado. Los precios equivalen a los valores, y no contienen otra cosa que no sea la absoluta equivalencia del trabajo incorporado a los bienes. De esta manera se cierra el circuito de la economía en valores, que sustituye a la de precios. Se acabó la explotación de los hombres por sus prójimos. Cada ser humano recibe el valor completo que él agregó a los bienes o servicios" (Dieterich, 2005:40).

Esto remite al problema, ya previsto por Marx, del trabajo calificado frente al simple.

"Habrá que incluir en la teoría sobre el valor del trabajo todas las actividades humanas que trasciendan el autoabastecimiento del individuo. Se trata, ante todo, de las actividades que hoy día se reúnen bajo el término servicios (...); en pocas palabras, todas las actividades cuyos resultados no entran directamen- 
te a los bienes. Cuando hayamos analizado el tiempo invertido $\mathrm{y}$, en consecuencia, el valor de cada bien, podremos reducirlo a un común denominador con los servicios mediante el cálculo del tiempo invertido. Esta conmensurabilidad de los servicios con los trabajos de la producción (...) pone a toda la economía bajo un principio uniforme y su circuito puede cerrarse sobre una base equivalente (...) que incluye a todo individuo, independientemente del tipo de actividad que realice" (Dieterich, 2005:41)

La solución de Dieterich es el reconocimiento de que se está en una etapa de transición en la cual ciertas injusticias no son posible abolirlas rápidamente y en el cual debe implementarse un sistema de gratificaciones que resuelva el problema de los estímulos a los que realizan un trabajo más peligroso, los que se esfuerzan más y los que tienen más conocimientos.

"Los principios del valor objetivo, de la equivalencia y de la planificación democrática son indudablemente los ejes fundamentales de la economía justa del futuro (...) Pero todo indica que, para la fase de transición, esos principios tendrán que ser adecuados a las condiciones del entorno que se darán en el proceso de superación de la economía de mercado (...) Tendrán que introducirse, muy probablemente, en la economía mixta de transición, modificaciones que tomen en cuenta realidades de la condición humana dentro del capitalismo: la importancia de los estímulos materiales, el afán de poder, las envidias, tendencias hacia la corrupción, el narcisismo, el autoritarismo y el consumismo, entre otras, (además de) la relación entre la productividad del trabajador y su retribución material ( $y$ el tema de) las condiciones de trabajo" (Dieterich, 2005:64).

De modo que el ideal de justicia que todos tengan la misma gratificación por el mismo trabajo sólo se conseguiría en el comunismo, tal cual lo planteaba Marx. Así, problema de la injusticia económica no reside en el dinero, ni tiene que ver con que una economía sea monetarizada o si funciona en base al intercambio de especies. La injusticia para Dieterich existe cuando se intercambia un producto "A" por otro producto "B", y los valores de esos productos -el tiempo de trabajo para producirlos- no son iguales; es decir, no se cambian equivalentes.

En este sentido, no sería la estatización generalizada de la propiedad privada la que resolvería el problema del mercado y la justicia distributiva, Para Dieterich el problema fundamental del socialismo hoy es un problema de complejidad informática y del establecimiento de un sistema matemático-contable de naturaleza socialista ${ }^{9}$, fundado en el valor, para poder realizar los intercambios sin sujeción a los precios del mercado, al

9 Según Dieterich (2005), Arno Peters ha avanzado en la resolución del problema conceptualmatemático de la medición del valor, a través de una matriz, que denominó "Rosa de Peters", que permite calcular el valor de cualquier producto. 
Quinto momento de la Quinta República: El socialismo del siglo XXI

Mujica Chirinos, Norbis y Rincón González, Sorayda

lado del sistema contable capitalista basado en el precio, para construir un circuito económico productivo y de circulación paralelo al de la economía de mercado capitalista. Es decir, se acepta la convivencia de los dos sistemas hasta que, paso a paso, el sistema basado en el vaIor -socialista- desplace al basado en el precio -capitalista-. Esta sería la única manera de poder hablar de una economía socialista, en términos de la economía política marxista: la sustitución del mercado por una economía de las equivalencias, basada en el valor y la planificación democrática de las mayorías (Dieterich, 2005; Guerra, 2006).

"La transición hacia la economía equivalente es facilitada y activada por la rápida computarización de la economía, administración y vida privada, ya que el entrelazamiento de la producción, la distribución, el consumo y la prestación de servicios puede garantizarse por medio de la computadora (...) La única manera de lograr una economía justa (socialista) es mediante el intercambio de esfuerzos laborales iguales (equivalentes), entendiéndose por valor la cantidad de tiempo promedio necesario para la producción del producto. La determinación del valor objetivo es un problema metodológico-científico; la implementación del intercambio de valores iguales (equivalentes), es un problema de poder. Lo primero se resuelve con las matemáticas avanzadas y la informática; lo segundo con la Democracia Participativa" (Dieterich, 2005:41 y 62).

EI Segundo Eje de la propuesta de Dieterich es la Democracia Directa; parte de la crítica a la sociedad capitalista, afirmando que los derechos políticos de la democracia representativa -burguesason una formalidad y que tal representatividad es un mito; sin embargo, serían necesarios, pero no suficientes, para la sociedad democrática del futuro (Dieterich, 2005; Guerra, 2006).

Afirma que la división de poderes constituye la base del Estado de Derecho burgués y el único aporte de ésta para avanzar en la convivencia política. Así miso, que los mecanismos formales -división de poderes, constitución, sistema electoral, parlamento, estructura Federativa el Estado, los medios de comunicación, acceso a la propiedad privada, estado de derecho, dicotomía público-privado- han sufrido una involución o neutralización por parte de la élites dominantes que los convierten en simples teoremas declaratorios (Dieterich, 2005).

Sin embargo, requieren su profundización y ampliación como paso previo al establecimiento de la democracia directa participativa, definida como la capacidad real de la mayoría ciudadana de decidir sobre los asuntos públicos, por lo que se trataría de la ampliación cualitativa de la democracia formal cuyo único poder de decisión radica en el sufragio universal. En la democracia directa participativa y plebiscitaria dicha capacidad no sería coyuntural, sino permanente y extensiva a literalmente todas las esferas de la vida social.

"El concepto democracia participativa se refiere a la capacidad real de la mayoría ciudadana de decidir sobre los principales asuntos públicos de la nación. En este sentido se trata de una ampliación cualitativa de la democracia formal (...) En la democracia participativa, dicha capacidad no será coyuntural 
y exclusiva de la esfera política, sino permanente y extensiva a todas las esferas de la vida social, desde las fábricas y los cuarteles hasta las universidades y medios de comunicación" (Dieterich, 2005:49).

Este estadio democrático marcaría el final de la democracia representativa y su institucionalidad; es decir, parlamento, sistema electoral, medios de comunicación y producción, la gran empresa y el Estado.

"Se trata del fin de la democracia representativa -en realidad sustitutiva- y su superación por la democracia directa y plebiscitaria (...) El parlamento y el sistema electoral de la partidocracia (...) no tendrán lugar en la democracia futura (...) Lo mismo es válido para los monopolios de la adoctrinación (televisión, radio y prensa) y de la producción (...) Y el Estado, cual organización de clase, irá por el mismo camino" (Dieterich, 2005:49).

Así, el socialismo del siglo XXI se materializaría en tres etapas: 1 . la superación del capitalismo global; 2. la fase intermedia de convivencia de los dos medios de producción -el capitalismo que no ha muerto y el socialismo que está naciendo-; 3. la etapa final es la sociedad $\sin$ economía de mercado, sin Estado y sin gobierno (Dieterich, 2005; Guerra, 2006).

"La democracia representativa fue un eslabón indispensable en la evolución hacia la democracia directa, mientras no existían los medios técnicos y culturales para la participación de las masas. Esta etapa ha pasado (...) No cabe duda, que el fin del egoísmo, de la codicia y de la explotación, que le son inherentes al principio de equivalencia, con- ducirá a cambios tan profundos en la manera de pensar y actuar, que después de su implantación general, será posible hablar, en términos generales, de un nuevo ser humano (...) Superada la división entre el trabajo intelectual y manual; abolido el yugo extenuante y brutalizador de la plusvalía; vencida la discriminación de colores, sexo e ingreso y franqueado el abismo entre campo y ciudad, el ser humano se realizará en las tres fuentes de nuestro ser: el trabajo, el eros y el saber" (Dieterich, 2005:49).

\subsection{La Propuesta de Reyes}

La propuesta del Prof. Oscar Reyes (2006) gira alrededor de cuatro ideas-fuerza: Régimen Político, Régimen de Propiedad, Sistemas de Producción y Modelo de Justicia Distributiva, y su elaboración la realiza basado en análisis de los discursos del Presidente Hugo Chávez. Parte de lo que es el socialismo Marxista, aclarando que sus ideas, si bien tienen algún asidero en Marx, también se separan en aspectos claves de su propuesta. Sólo busca exponer algunas ideas para el debate, tomando como base las directrices contenidas en la constitución de 1999, por lo que aclara que su propuesta no es el socialismo del siglo XXI. Presentamos su propuesta de manera sucinta.

Con respecto al régimen político, su apreciación es que se trata de una democracia mixta. Con eso, se separa de las ideas Marxistas puras, para quien la democracia era compatible con la dominación burguesa. Sería mixta, pues en la constitución se prevén mecanismos tanto 
Quinto momento de la Quinta República: El socialismo del siglo XXI

Mujica Chirinos, Norbis y Rincón González, Sorayda

participativos (referendos, consulta popular, iniciativa popular legislativa, contraloría social) como representativos (Asamblea Nacional, Parlamentos Regionales, Consejos Municipales). Así mismo, plantea que para que fuese directa (propuesta Dieterich), debería mantenerse a tino el poder constituyente originario.

"Una de las restricciones o ideas fuerza que más se repite cuando se hace análisis del discurso de quienes participan en este debate es que el régimen político de ese socialismo debe ser democrático y que su camino debe ser pacífico (...) Nos parece obvio que la democracia que se deriva de la constitución no es ni representativa pura ni participativa pura (...) Sería preferible hablar de sistemas mixtos, regímenes donde se mezclan varios tipos de magistraturas participativas directas con algunas otras representativas, dado que la realidad se resiste a ser contenida en los mapas y modelos y siempre quedan retazos por fuera que no caben dentro de las clasificaciones" (Reyes, 2006:88 y 89).

El régimen de propiedad sería mixto, conviviría la propiedad privada individual con propiedad estatal y propiedad colectiva. Establece algunos límites éticos. El límite ético de la propiedad privada sería un principio que toma de Rawls: tanto como sea posible en la medida que esa acumulación no restrinja el acceso de cualquier otro miembro de la sociedad a otros recursos y riquezas de la nación. El límite ético de la propiedad estatal y colectiva es que no debe ser inútil, que los funcionarios encargados de empresas públicas o cooperativistas tengan el im- perativo moral de ser productivos -al menos como sus pares capitalistas- para que el nuevo sistema sea viable.

"El régimen de propiedad en un socialismo del siglo XXI parecería tender a ser de tipo mixto. Esto de entrada suena antimarxista, pero no es una idea del autor, sino una inspección somera del discurso entre diversos voceros del proceso que se han expresado sobre este problema señalando que se va a mantener la propiedad privada (...) ¿Cómo puede ser socialista un sistema donde hay diversos tipos de propiedad? Tal vez siga siéndolo en la medida que el sistema respete el espíritu de justicia implícito en la denuncia de Marx, en la medida en que la propiedad no genere graves injusticias, porque pareciera que cierta desigualdad va a ser inevitable" (Reyes, 2006:92).

Así como la propiedad es mixta, el sistema de producción también lo sería. Dado que se acepta la propiedad privada, se acepta en primera fase -hasta que se implante un régimen de producción igual de eficiente y más justo distributivamente- el capitalismo individual o privado con controles. El límite ético sería que cubrieran con creces las necesidades sociales de sus trabajadores y que tuvieran responsabilidad social e intergeneracional en el tema ecológico. Los modelos alternativos serían empresas en cogestión estado-empresarios-trabajadores, empresas altruistas, cooperativas y empresas comunales tanto de producción de bienes y servicios como de resolución de problemas públicos, manteniendo el imperativo de ser tan o más productivas y eficientes que las empresas capitalistas para que el sistema sea viable. 
"¿Es posible sustituir el capitalismo -aunque sea paulatinamente- con un sistema alternativo de producción que sea más justo y a la vez más igual de productivo? ¿O al menos se le pueden injertar modelos alternativos sin destruirlo mientras mantiene su condición de modo de producción predominante en la nación? (...) La pregunta es vital porque además establece un límite ético muy complejo. Si la productividad de los sistemas alternativos de producción es el paradigma del nuevo socialismo, y si ese socialismo en principio no está reñido con una producción liderada por empresarios privados con solidaridad social, hay que estar seguros de si es conveniente o no sustituir totalmente un sistema de producción por otro hasta que el nuevo sistema no haya demostrado que es tanto o más productivo que el viejo, aunque con una más justa distributiva, que es lo que lo haría preferible (...) De manera que el quid de la cuestión es encontrar sistemas alternativos de organizar la producción que sean tanto o más eficientes que el capitalismo y más susceptibles de repartir mejor la riqueza de la nación, es decir, tan efectivos o más que el clásico mercado capitalista, al menos en su formulación teórica" (Reyes, 2006:95).

La justicia distributiva se fundamenta en la repartición de bienes y activos -tierras, acciones de empresas en cogestión, recursos para cooperativas y empresas comunitarias-, así como de recursos o capital político: participación, contraloría social, descentralización, transferencia estado-sociedad. Se mantendría el Estado de Bienestar implícito en el Seguro Social, reformado para que todos puedan cotizar. También acepta empresas alternativas de prestación de servicios -cooperativas, comunitariascomo seguros populares, banca popular, etc. Se mantiene igualmente el Estado de Bienestar en materia de educación primaria y secundaria, que es una de las maneras más efectivas de redistribuir.

"A nuestro juicio, la justicia distributiva tiene mucho que ver con la gestión social de Estado. Es labor del Estado -sea socialista o socialdemócrata- garantizar al menos una buena educación básica y secundaria pública, medicina pública y seguridad, para que quienes no partan con ventajas tengan al menos ciertas redes en las cuales caer en caso de contingencias negativas. Hasta donde entendemos, la mejor manera de redistribuir la riqueza y de dar justicia distributiva es mediante servicios públicos eficientes y mediante un Estado de Bienestar viable, como el Estado Alemán. Puede parecer lugar común, pero dado que el Estado monopoliza los recursos recabados en los impuestos, además de la riqueza fruto del petróleo, la mejor manera que tiene el Estado para lograr una justicia distributiva aceptable -si aspira llegar a ser socialista- es mediante un Estado de Bienestar que funcione verdaderamente (Reyes, 2006:101).

\subsection{Socialismo del Siglo XXI desde el Gobierno}

Para comenzar el análisis de lo que el gobierno entiende como socialismo del siglo XXI, debemos recalcar, como se expresó anteriormente, que éste se constituye en un Quinto Momento a partir del año 2004, dado los elementos e ideas 
Quinto momento de la Quinta República: El socialismo del siglo XXI

Mujica Chirinos, Norbis y Rincón González, Sorayda

que se construyen alrededor de él. Básicamente se analizan dos documentos: $L i$ neas Generales del Plan de Desarrollo Económico y Social de la Nación 20072013 (MPD, 2007a) y el Proyecto Nacional Simón Bolívar: Todos los Motores a Máxima Revolución Rumbo al Socialismo (MPD, 2007b).

El documento Líneas Generales del Plan de Desarrollo Económico y Social de la Nación 2007-2013 (MPD, 2007a) está construido y organizado en torno a siete áreas temáticas; para los objetivos del presente trabajo, y por razones de tiempo y espacio, nos limitaremos a los postulados de tipo teórico-filosófico de las cuatro primeras áreas.

La primera de ellas, denominada Nueva Ética Socialista, comienza por declarar que para la consecución del Socialismo del Siglo XXI se necesitaría una refundación ética y moral de la nación, posible sólo en mediano plazo, y que supone un proyecto ético cuyo fin último es la suprema felicidad. Este proyecto ético parte de un diagnóstico de la situación actual, donde se releva: a- la confrontación entre el viejo sistema (capitalista) que no a terminado de fenecer, y el nuevo sistema (socialista) que está naciendo; b- la pobreza aun permanente; c- la persistencia de la sub-cultura de la corrupción y el soborno; y c- la utilización de los medios de comunicación como arma ideológica de la oligarquía (MPD, 2007a).

Basado en este diagnóstico, se plantea que el proyecto ético tiene como misión la superación de la ética del capital para configurar una conciencia revolucionaria sólo alcanzable mediante la lucha dialéctica por la transformación material de la sociedad, cuyos desafíos más des- tacados serían: 1. la superación positiva de la pobreza material y espiritual; 2. la construcción de un Estado ético o una nueva ética del hecho público; 3 . la civilidad o virtud por la que los ciudadanos se hacen responsables por la vida pública; 4. Institucionalidad como práctica de la justicia y la equidad; 5 . la tolerancia activa militante que asume las diferencias y las respeta. Este proyecto ético propone una ética cívica, pluralista y tolerante hasta ciertos límites, que asume las diferencias y las respeta, y toma como valores el amor, la corresponsabilidad moral, el ser social colectivo, el supremo valor de la vida, el valor del trabajo creador y productivo (MPD, 2007a).

"Por dentro de esta amplitud de tolerancia ante lo diverso, hay un núcleo de hechos y antivalores ante lo que no se puede ser indiferente ni tolerante, pues conducen a crear un estado de cosas donde la impunidad se convierte en algo normal y aceptado por todos. Ante la crueldad, ante la tortura, ante la discriminación racial, ante la violación de los derechos humanos, ante la violación de una mujer, ante el maltrato de los niños, ante las injusticias, ante la corrupción y ante otras muchas cosas de características similares no se puede ser tolerante, no se puede consentir" (MPD, 2007a: 4).

Plantea tres estrategias de política: Transformar la sociedad material y espiritualmente, desarrollar la conciencia revolucionaria y superar la ética del capital (MPD, 2007a).

La segunda área, La Suprema Felicidad Social, es definida como la visión a largo plazo que tendría como punto de partida la construcción de una estructura 
social incluyente que forme una nueva sociedad de incluidos en un nuevo modelo social, productivo, socialista, humanista y endógeno (MPD, 2007a).

"Las bases de las políticas de la construcción de una nueva estructura económica y social incluyente están contenidas en la Constitución de la República Bolivariana de Venezuela, en las tradiciones de lucha del pueblo venezolano y en la voluntad política del actual gobierno de avanzar hacia la construcción del socialismo (...) La estructura social de Venezuela está en proceso de transición hacia una formación económico social más incluyente, porque el gobierno está ejecutando, especialmente con las Misiones, un proceso de inclusión social masivo y acelerado, financiado por la nueva forma de utilizar la renta petrolera, lo que ha permitido avanzar en la cobertura y la universalización en la satisfacción de necesidades de identidad, alimentación, salud, educación, vivienda y empleo" (MPD, 2007a:7).

Las relaciones sociales de producción, definidas como socialistas, estarían basadas en formas de propiedad social -autogestionaria, asociativa y comunitaria- y formas de propiedad individual y pública (MPD, 2007a).

La política de inclusión económica y social formaría parte del sistema de planificación, producción y distribución socialista donde lo importante es el desarrollo de la propiedad social, la implementación de sistemas justos de intercambios contrarios al capitalismo, la superación de las diferencias entre trabajo intelectual y manual y reconocer el trabajo como única actividad generadora de valor y por tanto que legitima el derecho de propie- dad, orientado por el principio de cada cual según su capacidad, a cada quien según su trabajo, comenzando así por satisfacer las necesidades sociales básicas y superar las brechas y déficit persistentes. Así, la inclusión adquiriría su más elevado desarrollo cuando se personaliza su atención a los grupos sociales en situación de máxima exclusión, con lo que se continuaría con la política de focalización de los grupos objetivos de la política pública (Cf: MPD, 2007a).

En la tercera área propone la Democracia Protagónica Revolucionaria como expresión genuina de la verdadera democracia, que parte de los individuos organizados para el ejercicio pleno de la soberanía. Ésta reside en el pueblo, que puede dirigir por sí mismo al Estado sin delegar su soberanía. La democracia participativa es la voluntad general que se hace tangible en el ejercicio de la voluntad general la cual no puede enajenarse nunca. El ejercicio de la soberanía se realiza a través de la participación ciudadana en todos los asuntos públicos, ámbitos y niveles territoriales (MPD, 2007a).

"El cambio debe estar orientado a poner de relieve los elementos en común, que permitan construir una comunidad, no individuos aislados y egoístas atentos a imponer sus intereses a la comunidad, a esa entidad -comunidad- se entrega todo el poder originario del individuo lo que produce una voluntad general, en el sentido de un poder de todos al servicio de todos, es decir, sustentado moral y colectivamente, lo que obliga a que la conducta de los asociados, aunque tengan intereses particulares (voluntades particulares), para poder ser moral deberá estar guiada por la justicia, es de- 
Quinto momento de la Quinta República: El socialismo del siglo XXI

Mujica Chirinos, Norbis y Rincón González, Sorayda

cir, por principios de igualdad y de libertad" (MPD, 2007a:12).

Esta democracia se basa en la defensa, conservación y desarrollo de la vida humana y en la corresponsabilidad solidaria por la vida del otro en comunidad; en ella el Estado garantiza los contenidos materiales que exigen la realización del bien común, la justicia está por encima del derecho y las condiciones materiales para garantizar el bien de todos -educación, salud y trabajo- están por encima de la simple formalidad de igualdad ante la ley y la tiranía mercantil. Así mismo, es ético, solidario, preserva los derechos a la defensa de la vida y la solidaridad en comunidad como sentido de la cooperación social (MPD, 2007a).

"En la democracia protagónica revolucionaria el Estado es ético, de carácter solidario, preserva los derechos a la defensa de la vida y la solidaridad en comunidad como sentido de la cooperación social. Está fundado en la conciencia ética y no en la represión, pues no admite que intereses particulares se impongan al interés general de la sociedad y el bienestar de todos" (MPD, 2007a:13).

El logro y afianzamiento de esta democracia protagónica revolucionaria estaría determinada por la necesidad de darle a la política carácter público, la utilización del poder político como garantía del bienestar y la igualdad social, la participación en todos los ámbitos públicos como garantía de ejercicio de la soberanía, el enfrentamiento a la corrupción, la integración en redes de las organizaciones populares, la coherencia entre discurso y praxis política de la institucionalidad pública y el control social de los me- dios de comunicación masivos y su utilización como instrumento de formación (MPD, 2007a).

En lo económico, como cuarta área, se propone el Modelo Productivo Socialista, orientado hacia la eliminación de la división social del trabajo, de su estructura jerárquica y de la disyuntiva entre satisfacción de necesidad y producción de riqueza. Responderá a las necesidades humanas y estará menos subordinada a la reproducción del capital.

"La creación de riqueza se destinará a satisfacer las necesidades básicas de la población de manera sustentable y en consonancia con las propias exigencias de la naturaleza en cada lugar específico (...) Establecer un Modelo Productivo Socialista con el funcionamiento de nuevas formas de generación, apropiación y distribución de los excedentes económicos y una nueva forma de distribución de la renta petrolera, lo que será reflejo de un avance sustancial en el cambio de valores en el colectivo, en la forma de relacionarse los individuos con los demás, con la comunidad, con la naturaleza y con los medios de producción" (MPD, 2007a:23).

En este modelo productivo, el Estado conservará el control total de las actividades productivas que sean de valor estratégico para el desarrollo del país y de las necesidades y capacidades productivas del individuo social. Estará conformado por las Empresas de Producción Social (EPS), germen hacia el socialismo del siglo XXI, aunque persistirán empresas del Estado y empresas capitalistas privadas. Por EPS se entiende aquellas unidades económicas de producción de bienes y servicios, eficientes, en las que 
no existe división social ni técnica del trabajo ni trabajo alienado y en las que el mismo tiene significado propio y sin privilegios jerárquicos. Los bienes producidos serán de calidad competitiva tanto en al mercado interno como externo y los excedentes se repartirán entre los trabajadores según la cantidad de trabajo aportado (MPD, 2007a).

Sin duda alguna, para acometer estas metas, se haría necesaria una transformación institucional profunda, que incluye la reforma a la constitución, pues en la misma, aun y cuando reconoce las distintas formas de propiedad, no coloca a alguna por encima de otras; sólo prevé que el Estado fomentará formas alternativas a la propiedad privada.

En este sentido, se propone el Proyecto Nacional Simón Bolívar. Todos los Motores a Máxima Revolución Rumbo al Socialismo (MPD, 2007b). Este proyecto esta basado en cinco áreas. La primera, propone una Ley Habilitante, como vía directa hacia el socialismo, que implica la transformación institucional general, en lo político, económico, social, internacional y ético-cultural realizada desde el ejecutivo, por encima de la Asamblea Nacional que delegó en el Presidente la facultad de legislar y realizar leyes a lo largo de año y medio.

Esta primera área prevé la estatización-nacionalización de empresas estratégicas, como las del sector eléctrico, del sector comunicaciones y, a juzgar por los últimos acontecimientos, del sector medios de comunicación.

La segunda área plantea una $R e$ forma Constitucional; por supuesto, una transformación institucional general en todos los ámbitos, requiere que esté en concordancia con el marco constitucional. Se considera que la actual constitución presenta un primer acercamiento a la construcción del socialismo, pero para avanzar hacia la República Socialista de Venezuela (sic), se requieren las reformas necesarias para ponerla a tono con el Plan Nacional y con la reforma institucional.

Se reconoce que el la actual constitución "quedaron infiltrados muchos gazapos del viejo régimen” (MPD, 2007b:6) y otros elementos no quedaron bien delineados -por ejemplo áreas estratégicas que deben quedar en control del Estado-.

La tercera área propuesta es Moral y Luces, dedicada al sector educativo -en todas las áreas y ámbitos- y de formación en valores socialistas; es decir, el componente ideológico de la estructura propuesta.

La cuarta área la denominan $L a$ Nueva Geometría del Poder o el reordenamiento socialista del territorio, y tiene que ver con una nueva manera de distribuir el poder y organizar la división político-territorial del país, heredada de la cuarta república. Bajo esta premisa, se podría suprimir y crear municipios y hasta estados.

La última área presentada es la $E x$ plosión del Poder Comunal o Democracia Protagónica, Revolucionaria y Socialista, referido al empoderamiento de las comunidades a través de los Consejos Comunales como herramientas del poder popular constituyente y la creación de ciudades federales y ciudades comunales, donde no existan juntas parroquiales, alcaldías ni consejos municipales, sino poder comunal. Se evidencia aquí la intención de eliminar una institucionalidad ya 
Quinto momento de la Quinta República: El socialismo del siglo XXI

Mujica Chirinos, Norbis y Rincón González, Sorayda

establecida -municipalización del país- y el establecimiento de otra diferente.

Como se evidencia, es indispensable, para la viabilidad del PDESN-20072013, el impulso y ejecución del Plan Simón Bolívar como vía rápida a la propuesta de transformación socialista del país. Es clara la intención de cambio de régimen económico y político, por lo que la transitoriedad, características de los momentos anteriores, culminaría en esta nueva etapa.

\section{A Manera de cierre}

De acuerdo a lo hasta aquí expuesto, es evidente la intención del Gobierno actual de avanzar hacia otro tipo de estadio social, que llama socialismo, que conforma, según nuestro criterio, un quinto momento en el transito histórico que ha recorrido desde 1999.

Es también evidente las coincidencias y diferencias con el proyecto socialista propiamente Marxista, coincidencias referidas al principio que guía la justicia distributiva -aun cuando se aprecia que todavía se hace marcado énfasis en la focalización y compensación-, la definición de la democracia comunal -expresión de la explosión del poder popular- que presenta rasgos con lo descrito por Marx en la Comuna de París, con la consideración del trabajo como actividad fundamental del hombre generadora de riqueza y la propensión a eliminar la separación entre el trabajo intelectual y manual, entre otras.

La diferencia fundamental se percibe en el problema de la propiedad privada y del Estado, que Marx abogaba por el desaparecimiento de ambos, mientras la propuesta gubernamental acepta la existencia -en un primer momento- de ambos tipos de propiedad y se percibe un peligroso fortalecimiento del Estado al viejo estilo soviético. En este sentido, el modelo a aplicar sería uno de transición hacia el comunismo; es decir, un modelo de economía mixta, con intervención activa Estatal en la economía y como financiador de iniciativas comunitarias, cooperativas y de cogestión, pero como un paso más hacia el tránsito y establecimiento de una economía socialista, centralizada y controlada desde el Estado. En este sentido, la conversión de la Misión Vuelvan Caras a la Misión Che Guevara ${ }^{10}$, es evidencia de las intenciones últimas del gobierno.

En este sentido, se perciben coincidencias profundas con la propuesta Dieterih, que toma de Marx, incluso en la periodización que hace de los distintos momentos para alcanzar el socialismo del siglo XXI -que prevé un período de convivencia entre ambos modelos productivos- y la aplicación de la economía de las equivalencias.

10 Según la Gaceta Oficial N 38.757 del 29 de Agosto de 2007, se crea, con carácter permanente la Comisión Presidencial para la Formación Ideológica y Política y la Transformación de la Economía Capitalista en un Modelo de Economía Socialista , la cual tendrá por finalidad el estudio, formulación, coordinación, seguimiento y evaluación del Plan Extraordinario "Misión Che Guevara" con el objeto de incorporar a los miembros de la comunidad organizada en el proceso de transformación económica y social del Estado. 
También se perciben coincidencias con lo propuesto por Reyes, en el sentido que su propuesta dibujaría, de manera más realista, el régimen transitorio -socialismo del siglo XXI- que llevaría al establecimiento de un sistema comunista, aun cuando el principio de justicia lo toma de Rawls y no de Marx, y lo relacionado con la productividad y efectividad del nuevo sistema, que debería ser mayor o igual al que se quiere suplantar, aunque no se percibe en las propuestas del gobierno una discusión en detalle sobre este asunto; sólo que las EPS deben ser productivas y efectivas. Donde existen algunas diferencias es en la discusión acerca del tipo de Estado necesario para el Socialismo del Siglo XXI y sus áreas de actuación prioritarias. Reyes propone un Estado de Bienestar renovado y efectivo en áreas prioritarias -salud, seguridad social, educación, etc.-, mientras de la propuesta gubernamental se desprende un Estado centralizado, controlador y todopoderoso.

Se aprecia, entonces, una clara determinación de que se quiere ir hacia otro tipo de organización político, económico, social y cultural de la sociedad. De allí que no es extraño las decisiones de estatización tomadas con respecto a algunos medios-señal de Radio Caracas Televisión-y sectores -como el petrolero, comunicaciones, electricidad, siderúrgica- y las amenazas de expropiación a otros -banca, agroindustria, cemento, entre otras-.

Pensamos que el peligro del cambio propuesto se halla en la radicalización de la polarización social por la que atraviesa el país en la actualidad. Es evidente que hay sectores numerosos que apoyan y adversan el proyecto que, por las señales que el gobierno emite, no permite pensar en una salida concertada y dialogal al problema, aun cuando en el Plan de Desarrollo Económico y Social de la Nación 2007-2013 se habla de la tolerancia, pero restringida por un límite ético determinado por el propio Estado. Este hecho fue previsto por Marx en su análisis de la comuna de París, de manera que no es extraña la actitud de descalificación, ofensa y discriminación tomada desde el gobierno contra toda manifestación de disidencia o crítica a sus políticas. Es esta actitud la que ha producido nuevas formas de exclusión -exclusión selectiva y autoexclusión- que han derivado en una ciudadanía de tipo selectiva o dividida.

Así mismo, existe clara una intención de querer establecer una nueva institucionalidad y división política-territorial, al estilo propio de lo descrito por Marx en la Comuna de París, con el empoderamiento de las comunidades -vía consejos comunales- y la creación de ciudades comunales y comunas, dependientes directamente de la Presidencia de la República.

\section{Referencias Bibliográficas}

Alvarado, Neritza (2004). "Gestión Social de la Pobreza y Exclusión en Venezuela a la Luz de las Misiones Sociales. Balance y Perspectivas (2003-2004)". Revista Venezolana de Análisis de Coyuntura. Vol. X. № 2. Julio-Diciembre. IIES Dr. Rodolfo Quintero. UCV. Caracas. Pp. 25-56.

Azocar, Gustavo (2007). De la Lista Tascón a la Lista Golinger....!!!!. Documento en Línea. Disponible: http://www.gustavoazocar.com/blog/?p=26 
Quinto momento de la Quinta República: El socialismo del siglo XXI

Mujica Chirinos, Norbis y Rincón González, Sorayda

Cabezas, Rodrigo (2002). "Más allá de un control de cambios urge profundizar el ataque al déficit fiscal". La Verdad, Maracaibo, miércoles, 13 de febrero, cuerpo C, p. 1.

Castellano, Alberto (2003). "Orientación teórica en la aplicación de la política monetaria y cambiaria en el caso venezolano durante el período 1998-2002". Revista de Ciencias Sociales, Vol. IX, $\mathrm{n}^{\circ} 2$, Instituto de Investigaciones. FCES, LUZ. Maracaibo, mayo-agosto, pp. 303-310.

Chávez Frías, Hugo (2002). "El dólar flota a partir de hoy". Panorama, Miércoles 13 de febrero, cuerpo 2, p. 1.

Clarembaux, Patricia (2007). Se oficializó la Lista Tascón. Tal Cual. Jueves, 26 de julio. Documento en Línea. Disponible: http://www.megaresistencia.com/ content/view/115/

CORDIPLAN (1999a). Programa Económico de Transición 1999-2000. Sin Edit, Sin Edic, Caracas, $40 \mathrm{pp}$.

Dieterich Steffan, Heinz (2005). EI Socialismo del Siglo XXI. S/Edit. S/Edic. Documento en Línea. Disponible: http:// www.puk.de/download/elsocialismo.pdf

Goméz, Irey (2003). Política social y crisis en Venezuela. Ponencia presentada en el XXIV Congreso de la Asociación Latinoamericana de Sociología (ALAS), Arequipa, Perú, del 4 al 7 de noviembre de 2003.

Guerra, José (2006). ¿Qué es el Socialismo del Siglo XXI? S/Edit. S/Edic.

Jatar, Ana Julia (2006). “De la 'Lista Tascón' al 'Aparheid' del Siglo XXI". EI Nacional. Documento en Línea. Disponible: http://www.noticias24.com/actualidad $/ ? \mathrm{p}=555$

Machado, Gustavo (2000). Análisis y perspectivas de la política económica en Venezuela año 1999. Informe final de becaría académica, Instituto de Investigaciones. FCES, LUZ, marzo.

Maingon, Thaís (2006). "Caracterización de las Estrategias de la Lucha Contra la Pobreza-Venezuela, 1999-2005". Fermentum. Revista Venezolana de Sociología y Antropología. Año 16. № 45. Enero-Abril 2006. Centro de Investigaciones en Ciencias Humanas. Universidad de los Andes. Pp. 57-99.

Marx, Carlos (1972). Manuscritos Economía y Filosofía. Alianza Editorial. Cuarta Edic. Madrid.

Marx, Carlos (1974a). "Crítica al Programa de Gotha", en Marx, Carlos y Engels, Federico. Obras Escogidas, Tomo III. Editorial Progreso. Moscú.

Marx, Carlos (1974b). Miseria de la Filosofía. Ediciones de Cultura Popular. Tercera Edic. México.

Marx, Carlos (1976). Salario, Precio y Ganancia. Editorial Progreso. Moscú.

Marx, Carlos (1977). El Capital. Crítica de la Economía Política. Vol. I. Fondo de Cultura Económica. Décima Tercera Impresión. Bogotá.

Marx, Carlos y Engels, Federico (1982). La Ideología Alemana. Editorial Pueblo y Educación. La Habana.

Marx, Carlos (2003). La Guerra Civil en Francia. Fundación Federico Engels.1era Edición. Madrid. En MARX, Carlos y ENGELS, Federico. Obras Escogidas, Tomo II. Editorial Progreso. Moscú.

Marx, Carlos y ENGELS, Federico (2005). Manifiesto Comunista. Prologado, explicado, anotado y glosado. Documento en Línea. Disponible: htpp:// www.manifiestoprograma.es/media/ 0/marxengels_manifiestocomunista. pdf

Ministerio de Planificación y Desarrollo (MPD) (2000a). Programa de gobierno: La propuesta de Hugo Chávez para continuar la revolución. Documento 
en Línea. Disponible: http://www. mpd.gov.ve, consulta: mayo, 2000.

Ministerio de Planificación y Desarrollo (MPD) (2000b). Programa económico año 2000. Documento en Línea. Disponible: http://www.mpd.gov.ve, consulta: mayo, 2000.

Ministerio de Planificación y Desarrollo (MPD). (2001a): Líneas Generales del Plan de Desarrollo Económico y Social de la Nación 2001-2007, [Documento en Línea]. Disponible: http://www. mpd.gov.ve [Consulta: Marzo, 2001a].

Ministerio de Planificación y Desarrollo (MPD) (2001b). Programa económico 2001. Documento en Línea. Disponible: http://www.mpd.gov.ve, consulta: mayo, 2001.

Ministerio de Planificación y Desarrollo (MPD) (2002a). Medidas en materia fiscal, cambiaria y productiva. Documento en Línea. Disponible: http://www. mpd.gov.ve, consulta: junio, 2002.

Ministerio de Planificación y Desarrollo (MPD) (2002b). Se garantiza la inversión social y se incentiva la producción. Documento en Línea. Disponible: http://www.mpd.gov.ve, consulta: junio, 2002.

Ministerio de Planificación y Desarrollo (MPD) (2002c). Propuesta para el consenso. Documento en Línea. Disponible: http://www.foronacional.gov.ve, consulta: junio, 2002.

Ministerio de Planificación y Desarrollo (2007a). Líneas Generales del Plan de Desarrollo Económico y Social de la Nación 2007-2013. S/E. S/Edit. Documento en Línea. Disponible: http://www.caracas.gov.ve/socialismosigloXXI/descarga/Plan.doc

Ministerio de Planificación y Desarrollo (2007b). Todos los Motores a Máxima Revolución, Rumbo al Socialismo. Corpozulia, Carbozulia. Carbones de la Guajira.
Ministerio de Salud y Desarrollo Social (MSDS) (2000). La revolución social en la V República. La política social de Venezuela. Caracas, sin edic., sin edit., Cumbre Mundial de Desarrollo Social, Ginebra, Suiza.

Ministerio de Salud y Desarrollo Social (MSDS) (2002). Plan Estratégico Social. El Desarrollo de un Pensamiento Estratégico en las Políticas Públicas por la Calidad de Vida y Salud. Sin Editorial. Sin Edición.

Movimiento Quinta República (MVR) (1998). Una revolución Democrática. La propuesta de Hugo Chávez para transformar Venezuela. Caracas, sin edic., sin edit.

Mujica Chirinos, Norbis (2002). "Estado y políticas sociales en Venezuela: ¿La Quinta República o el regreso al pasado?" Revista Venezolana de Gerencia, año 7, n 18, Universidad del Zulia, Vicerrectorado Académico, abriljunio, pp. 237-266.

Mujica Chirinos, Norbis y Alvarado, Neritza (2004). "Pobreza y Política Social en Venezuela Hoy: Reflexiones sobre su Concepción y Praxis". Revista BCV, Foros 10. Caracas, Abril. Pp. 145-163.

Mujica Chirinos, Norbis y Rincón González, Sorayda (2006). Caracterización de la Política Social y la Política Económica del Actual Gobierno Venezolano: 1999-2004. Revista Venezolana de Economía y Ciencias Sociales. Vol. 12. №1. Enero Abril. Universidad Central de Venezuela. Faces. Pp. 31-57.

Pérez Martí, Felipe (2001). "Los mecanismos de asignación de recursos e introducción a la cuarta vía". Documento en Línea. Disponible: http://www.foronacional. gov.ve, consulta: septiembre, 2002.

Pérez Martí, Felipe (2002). Un Estado mundial con solidaridad, para regular la convivencia global. Documento en Línea. Disponible: http://www.forona- 
Quinto momento de la Quinta República: El socialismo del siglo XXI

Mujica Chirinos, Norbis y Rincón González, Sorayda

cional.gov.ve, consulta: septiembre, 2002.

Pérez Martí, Felipe y Rodríguez, Francisco (2000). Estrategias económicas para el crecimiento con equidad. Documento en Línea. Disponible: http://www.foronacional.gov.ve, consulta: septiembre, 2002.

Reyes, Oscar (2006). Sobre el Socialismo del Siglo XXI en Venezuela. Stockholm Review of Latin American Studies. Issue № 1. November 2006. Documento en Línea: Disponible: http://
www.lai.su.se/gallery/bilagor/SRoLAS_No1_2006_pp84-104_Reyes. pdf

Soto, Fabiola (2006) "Luis Tascón prepara su "Lista II" para después del 3 de diciembre". Diario La Verdad. Política. Domingo, 22 de octubre.

Documento en Línea. Disponible: http://www. laverdad.com/detallenew.asp?idcat= 1 \&idnot $=47106$ 